\title{
Study on low-temperature treatment of nitrogen-containing wastewater by anaerobic biological filter with alkali-treated loofah-based filler
}

\author{
Jiaxu Guang ${ }^{1,2}$, Jiayi $\mathrm{Lu}^{1,2}$, and Qing Ting ${ }^{1,2, *}$ \\ ${ }^{1}$ National Environmental Protection Textile Industry Pollution Control Engineering \\ Technology Center,Shanghai,China \\ ${ }^{2}$ College of Environmental Science and Engineering, Donghua University,Shanghai,China
}

\begin{abstract}
In this study, a new type of anaerobic biological filter (ABF) packed with alkali-treated loofah filler and a filler-free suspension growth control group (SBR) were used to cultivate the inoculated activated sludge to improve the activity and low temperature tolerance of the enriched anaerobic ammonia oxidation bacteria in the reactor. The results show that $\mathrm{ABF}$ and SBR were acclimated and started quickly, and the total nitrogen removal rate was maintained at $70.9 \%$ and $63.7 \%$, respectively. Under the low temperature operating conditions, the total nitrogen removal rate of ABF maintained $59.9 \%$, which was $16.5 \%$ higher than that of SBR. The detected EPS in the biomass of ABF and SBR increased by $100 \%$ and $272 \%$, respectively, under low temperatures $\left(15^{\circ} \mathrm{C}\right)$. Metagenomic testing revealed that the anammox bacteria (Candidatus Brocadiae) were the dominant functional populations both in $\mathrm{ABF}$ and SBR systems, and their relative abundances were $22.5 \%$ and $11.38 \%$, respectively. In addition, it is found for the first time that anammox bacteria and denitrifying bacteria were the main contributors to EPS synthesis, which is important to the stable operation of the reactor at low temperature.
\end{abstract}

Keywords: Low temperature operation; Anammox; Alkali-treated loofah packing; Biological filter; Extracellular polymer; Metagenomic.

\section{Introduction}

In recent years, the process of Anaerobic Ammonia Oxidation (ANAMMOX) has attracted extensive attention and has been applied in the full-scale urban and industrial wastewater treatment plants ${ }^{[1]}$, with its advantages of low requirement for aeration and carbon sources, and yields less wasted sludge ${ }^{[2]}$. The enrichment of Anammox bacteria (AAOB) is the key to start the anammox process and improve their tolerance to cold environment rapidly. Studies have shown that the extracellular polymer secreted by AAOB may enhance their attachment to the biological filler and thus effectively alleviate the cell erosion phenomenon inside the

\footnotetext{
*Corresponding author: tq2004@dhu.edu.cn
} 
fillers, which could increase the mechanical and ecological stability of the system ${ }^{[3]}$.

Nowadays, most of the carrier fillers used in the process are natural or synthetic polymer fillers with simple structures and difficult for biofilm development. Loofah has the potential as good biological carrier filler ${ }^{[4]}$ with various advantages, such as low cost, porous structure with high specific surface area, non-toxic and high affinity for microorganisms growth ${ }^{[5]}$. The alkali-treated loofah material reduces the hydroxyl groups on the fiber surface and improves the fiber's microbial corrosion resistance and the service life of the filler.

Therefore, in this experiment, a new type of alkali-treated loofah-based filler biological filter was used to enhance the enrichment of the bacterial population in the reactor by adding porous structure fillers, and to improve the biological denitrification efficiency of the reactor. The research results can provide new ideas for maintaining the nitrogen removal efficiency of the anaerobic ammonia oxidation process under low temperature operation and improving the tolerance of the bacterial flora to low temperature environments.

\section{Materials and Methods}

\subsection{Sludge and Experimental Influent}

The inoculated sludge was sludge obtained from the second settling tank of Shanghai Songjiang Sewage Treatment Plant, with a sludge concentration of $10.08 \mathrm{~g} / \mathrm{L}$. The feeds applied in the experiments were the synthetic textile industrial wastewaters. During the overall denitrification, the formula of the wastewaters are: $120 \mathrm{mg} / \mathrm{L}$ of $\mathrm{NH}_{4}{ }^{+}$and $140 \mathrm{mg} / \mathrm{L}$ of $\mathrm{NO}_{2}^{-}, 100 \mathrm{mg} / \mathrm{L}$ of COD, $300 \mathrm{mg} / \mathrm{L}$ of $\mathrm{MgCl}_{2} \cdot 6 \mathrm{H}_{2} \mathrm{O}, 137 \mathrm{mg} / \mathrm{L} \mathrm{CaCl}_{2}$ and $30 \mathrm{mg} / \mathrm{L} \mathrm{KH}_{2} \mathrm{PO}_{4}$ were used as the nutrients of the reactor, and $\mathrm{NaHCO}_{3}$ was used to maintain the $\mathrm{pH}$ of the influent water within the range of $7.5 \pm 0.5$.

\subsection{Experimental Device Parameters and Operation}

The commercially available loofah was firstly cut into cylindrical slices with a thickness of $1 \mathrm{~cm}$ and soaked in $80 \% \mathrm{NaOH}$ solution for 12 hours and dried to prepare the new type of loofah-based filler. The experimental anaerobic biological filter (ABF) was packed with the above-mentioned alkali-treated loofah-based fillers. In addition, the control group (SBR) was used for comparison. The daily processing capacity of both devices were $30 \mathrm{~L}$. The experiment was divided into two phases: (1), the $35^{\circ} \mathrm{C}$ stable start-up operation phase and (2), the $15^{\circ} \mathrm{C}$ low temperature tolerance test phase. In the first stage, black opaque thermal insulation foam material were used to wrap the experimental device, and the two sets of biological filters were maintained at $35^{\circ} \mathrm{C}$ for 56 days. In the second phase, the reactor temperatures were reduced gradually. The temperature controlling system kept the two biofilters operated at a room temperature of $15^{\circ} \mathrm{C}$ for 42 days.

\subsection{Analysis Method}

The water samples were filtered through a $0.45 \mu \mathrm{m}$ membrane before monitoring. The alkaline persulfate digestion and ultraviolet spectrophotometry methods were used to determine the $\mathrm{TN}, \mathrm{NH}_{4}{ }^{+}-\mathrm{N}, \mathrm{NO}_{2}{ }^{-}-\mathrm{N}$ and $\mathrm{NO}_{3}{ }^{-}-\mathrm{N}$ of the wastewater samples. 
The sludge EPS was extracted by physical centrifugation method ${ }^{[6]}$. The polysaccharides and protein in the biomass were determined with anthrone-sulfuric acid assay ${ }^{[7]}$ and bicinchoninic acid(BCA) method ${ }^{[8]}$, respectively.

After the experimental low-temperature phase is over, the biomass in the biological filter were washed with physiological saline before dried with centrifugation and sent to the bio-company ( Shanghai Meiji Biotechnology Co., Ltd) for metagenomic analysis.

\section{Results and Discussion}

\subsection{Removal Effect of Nitrogenous Pollutants}

Start two sets of reactors, with the increase of operating time, the concentration of effluent $\mathrm{NH}_{4}^{+}$and $\mathrm{NO}_{2}^{-}$decreased gradually, and the denitrification efficiency increased gradually,

(a)

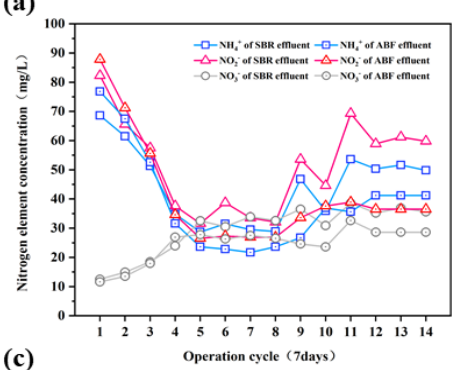

(9)

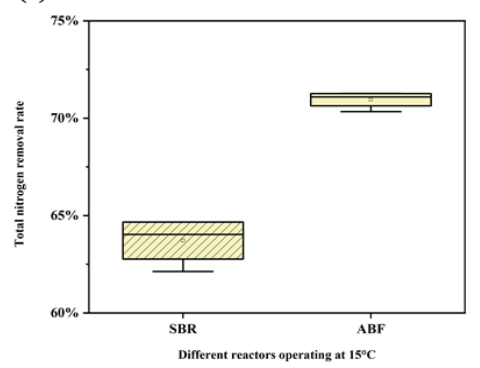

(b)
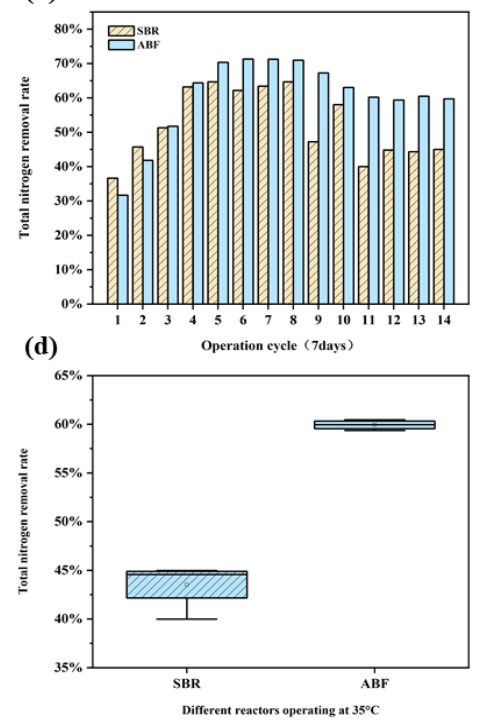

Fig. 1. Nitrogen removal performance of SBR reactor and ABF reactor after 14 weeks of operation: (a) nitrogen content of in and out water, (b) total nitrogen removal rate, (c) total nitrogen removal efficiency at $15^{\circ} \mathrm{C}$, (d) total nitrogen removal efficiency at $35^{\circ} \mathrm{C}$.

as shown in Figure 1(a). In the fourth week, the various indicators of the reactor stabilized. The denitrification efficiency of the SBR reactor and the ABF reactor were stabilized and reached average $63.7 \%$ and $70.9 \%$, respectively from the fourth week to the eighth week. Tthe denitrification rates were $97.6 . \mathrm{mg} /(\mathrm{L} \cdot \mathrm{d})$ and $90.9 \mathrm{mg} /(\mathrm{L} \cdot \mathrm{d})$, respectively, as shown in Figure 1(b). The total nitrogen removal rate was about $60 \%$, which was nearly $15 \%$ higher, compared with the SBR reactor. After the temperature control system was removed, as the temperature decreased, the removal rate of pollutants decreased significantly with the anammox bacteria inactivated gradually. The reason for this situation may be the sudden drop in temperature and the communities in the biomass shifted for re-adaptation as the environmental temperature decreased ${ }^{[9]}$. During the fifth to eighth week in the first stage and tenth to fourteenth week in the second stage, when the reactor was operating stably at different temperatures, the nitrogenous pollutants removal in $\mathrm{ABF}$ were much better than 
SBR as shown in Figure 1(c) and Figure 1(d).

\subsection{EPS Analysis}

The composition of EPS generally varies with different bacterial communities, and micro-ecological environment composed of water (97\%), extracellular polysaccharides, extracellular proteins, etc. ${ }^{[10]}$. The change of EPS composition were tracked in the operation of the two reactors. It was found that the main organic components of the biomass selected in the experiment were protein and polysaccharides, and the content of protein was much higher than that of polysaccharides, as shown in Table 1. The EPS inoculated with activated sludge was mainly composed of fixed extracellular polymer, which accounted for $84.5 \%$ and $86.1 \%$ of the total extracellular polymer in SBR and ABF reactors ${ }^{[11]}$.

Table 1. EPS content in activated sludge inoculated in the reactor.

\begin{tabular}{ccccc}
\hline Reactor & EPS category & S-EPS & LB-EPS & TB-EPS \\
\hline \multirow{3}{*}{ SBR } & Polysaccharide (PS) & 1.58 & 1.74 & 3.95 \\
& Protein (PN) & 5.71 & 11.95 & 21.95 \\
& Total amount of EPS & 7.28 & 13.69 & 25.90 \\
\hline \multirow{3}{*}{ ABF } & Polysaccharide (PS) & 1.22 & 1.11 & 2.94 \\
& Protein (PN) & 3.28 & 8.51 & 15.40 \\
& Total amount of EPS & 4.51 & 9.62 & 18.34 \\
\hline
\end{tabular}

The polysaccharide (PS) and protein (PN) EPS content tests were performed on the SBR reactor and the ABF reactor, respectively, as shown in Figure 2.

After the two reactors were operated for 50 days under temperature-controlled conditions, the soluble EPS content increased significantly. The activated sludge in the SBR reactor gradually increased its sedimentation and formed granular sludge, while the ABF

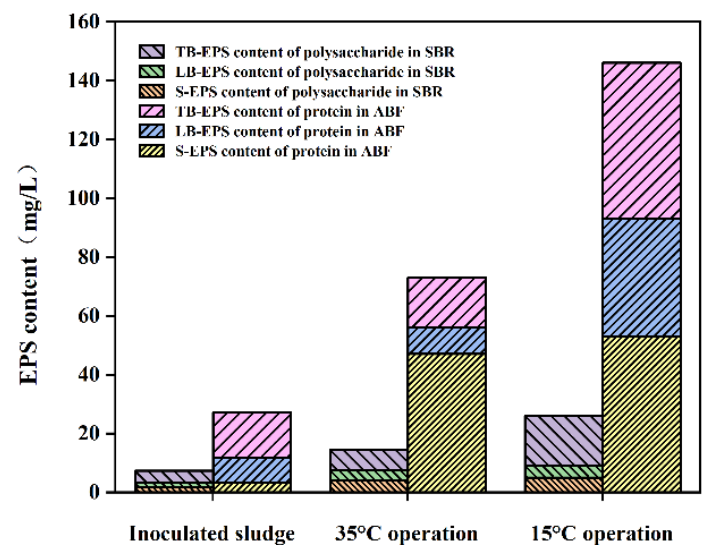

Fig. 2. Analysis of EPS content in the reactor at different operating stages.

reactor gradually formed a biofilm attached to the filler. The sludge form and the function of the biological community of the two gradually changed, so SBR and ABF reactors nitrogen removal performances were steadily improved with the stable operation of the reactor, as shown in Figure 1. 
With the advancement of the reactor operation process, the content of fixed and soluble polysaccharide EPS in the SBR reactor gradually increased. After the temperature control system was removed, the composition of soluble EPS remained almost unchanged, and the content of fixed EPS increased greatly. After 50 days of stable operation of the ABF reactor, the total amount of EPS increased significantly. Among them, the change of fixed EPS or TB-EPS was relatively small. After the temperature control system had been removed, the content of soluble EPS remained almost unchanged, and the content of fixed EPS has increased significantly (with an increase of $272 \%$ ).

\subsection{Analysis of Bacterial Colony Composition and EPS Synthesis Pathways}

Metagenomic sequencing and bioinformatics analysis were performed on ABF and SBR. Both reactors were detected for their biomass bacterial composition, which was dominated by "Candidatus_Brocadiae". Among them, the relative abundance of anammox in ABF and SBR were $22.5 \%$ and $11.38 \%$ respectively, as shown in Figure 3.

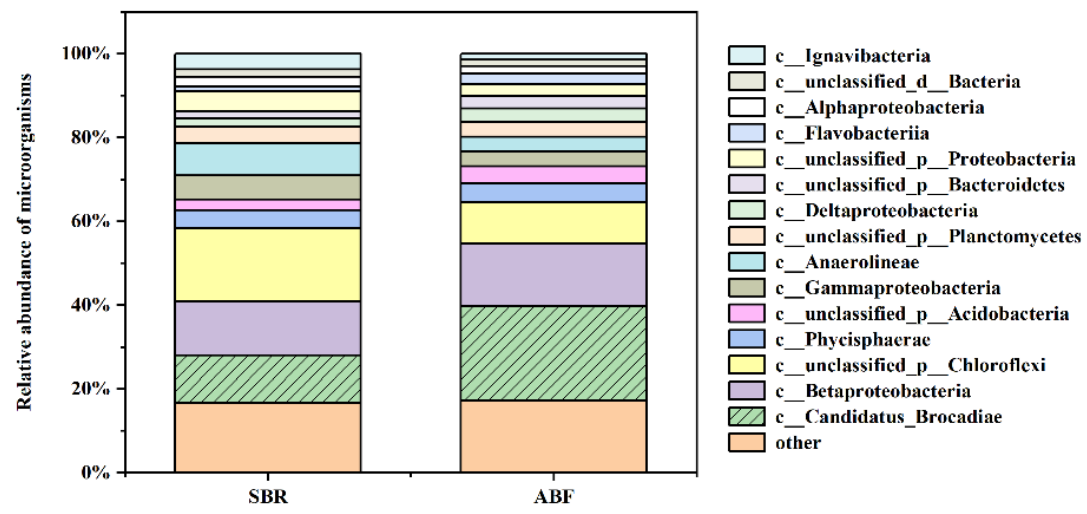

Fig. 3. The level composition of the microbial genus in the biofilter with an abundance of more than $1 \%$.

In addition, the accumulation of EPS could assist in developping cold resistance and buffering capacity to unfavorable growth factors such as low temperature and toxicity, which is the reason why the addition of fillers under low temperature conditions helps the bacterial community to grow better.

As shown in Figure 4, the anammox bacteria and denitrifying bacteria were the main

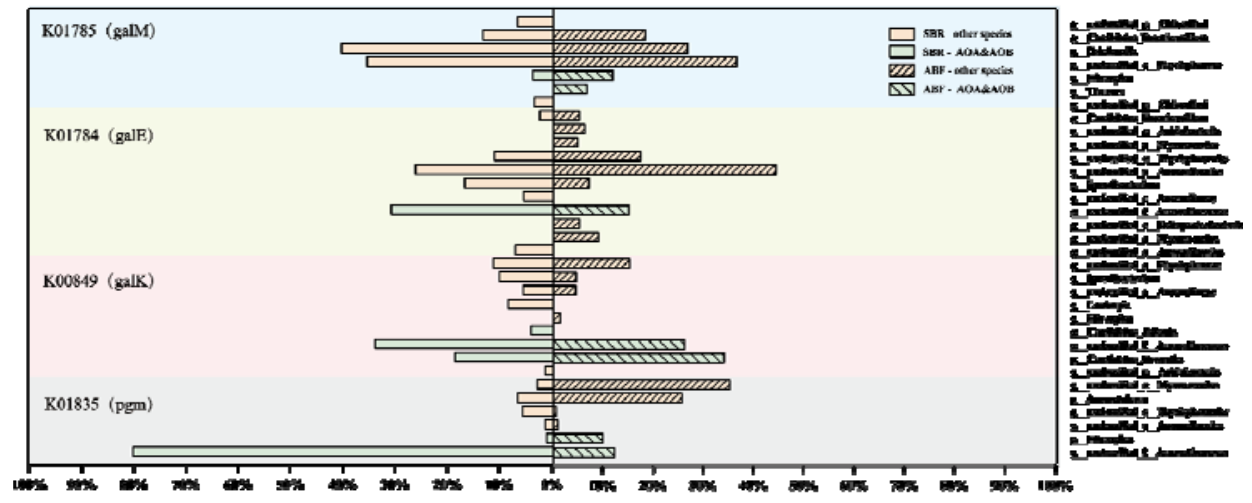

Fig. 4. The relative abundance of the four types of genes coding for EPS synthesis by different community members in the $\mathrm{ABF}$ and SBR operated under $15^{\circ} \mathrm{C}$ condition. 
functional populations that synthesize EPS. Among them, the genus of unclassified_f_Anaerolineaceae, Nitrospira, Candidatus_Brocadia, Candidatus_Jettenia, Thauera were the five typical ammonia oxidizing archaea (AOA) and ammonia oxidizing bacteria (AOB), which contributed high fraction of genes coding for different pathwaysinEPS synthesis.

Both reactors were dected for typical EPS synthesis pathways via the GALM, GALE, GALK and PGM. As shown in Figure 4, in the two EPS synthesis pathways of GALM and GALK, the AOA and $\mathrm{AOB}$ species in the $\mathrm{ABF}$ reactor accounted for $14.8 \%$ and $5 \%$ higher, respectively, than those in the SBR reactor. In the gene expression process of PGM and GALM, the species of AOA and AOB involved in EPS synthesis in $100 \%$ more than that in SBR. The above data showed that compared to the suspension culture of the SBR reactor, the ABF reactor with loofah as the filler not only promoted the growth and enrichment of the bacterial flora, but also potentially improved the adhesion efficiency of the ammonia oxidizing bacteria with the synthesied EPS. On the basis of the above experiments, a new method is proposed for the stable operation of the low-temperature environment bioreactor.

\section{Conclusions}

Using ABF and SBR to treat nitrogen-containing wastewater, the reactor can be started quickly when operating at $35^{\circ} \mathrm{C}$, and the average total nitrogen removal rate after 56 days of stable operation of the reactor were $70.9 \%$ and $63.7 \%$, respectively. In a low temperature environment $\left(15^{\circ} \mathrm{C}\right)$, the accumulation of EPS in ABF and SBR was positively correlated with the total nitrogen removal rate and low temperature tolerance of the reactor.

The relative abundance of dominant functional bacteria (Candidatus_Brocadiae) in $\mathrm{ABF}$ and SBR accounted for $22.5 \%$ and $11.38 \%$, respectively, which is an important biological factor for $\mathrm{ABF}$ with the low temperature tolerance.

AOA\&AOB colonies account for a relatively high proportion of the synthesis of EPS, which provides an energy basis for the denitrification of the biological community under low temperature conditions.

\section{Acknowledgement}

Carbon source regulation mediated by phosphorus recovery-low temperature resistance mechanism of biofilm nitrogen and phosphorus removal system (17K11319)

\section{References}

1. K.B. Alpaslan, D. Duygu, S. Neslihan, Water Sci. Technol, 78 (2018)

2. B. Kartal, W.J. Maalcke, N.M.D. Almeida, Nature, 479 (2011)

3. E. Steffen, F.M. Terence, R. Kristina, Water Sci. Technol, 74 (2016)

4. J. Shen, Y.M. Xie, X. Huang, J. Mech. Behav. Biomed. Mater, 15 (2012)

5. J. Shen, Y.M. Xie, X. Huang, Int.J. Impact Eng, 57 (2013)

6. T.T. More, J.S.S. Yadav, S. Yan, J. Environ. Manage, 144 (2014)

7. F. Leng, S. Sun, Y. Jing, Bulg. Chem. Commun, 48 (2016)

8. K. Pavel, K. Tatyana, B. Maria, Int. J. Pharm, 599 (2021)

9. T. Lotti, R. Kleerebezem, J.M. Abelleira-Pereira, Water Res, 81 (2015)

10. C. Pellicer-Nàcher, C. Domingo-Félez, A.G. Mutlu, Water Res, 47 (2013)

11. I. Sharif, E. Maria, O.J. A, Environ. Technol, 38 (2017) 